\title{
PLANO DIRETOR, INTERVENÇÕES E CONTRADIÇÕES NA PRODUÇÃO DO ESPAÇO URBANO DA ÁREA CENTRAL DE TERESINA (PI)
}

\author{
Silvana de Sousa Silva ${ }^{1}$ \\ Antônio Cardoso Façanha ${ }^{2}$
}

\section{RESUMO}

O artigo apresenta análises sobre as intervenções espaciais promovidas a partir das propostas contidas no Plano Diretor Urbano, sob a ótica dos agentes que atuam na produção espacial da área central de Teresina (PI). Nessa perspectiva, foram adotados como procedimentos o levantamento de referencial teórico, entrevistas e aplicação de questionários. A análise dos dados revelou contradições na atuação dos agentes durante os processos de elaboração e efetivação das ações pensadas para a área central de Teresina. Conclui-se, que a área central de Teresina assume relevância para um conjunto diversificado de agentes, no entanto, a atuação destes durante a elaboração das orientações contidas no Plano Diretor concorreu para a coexistência de aspectos que geram uma produção contraditória do espaço.

Palavras chaves: Intervenções Urbanas. Plano Diretor. Teresina (PI)

\section{PLAN DIRECTOR, INTERVENCIONES Y CONTRADICIONES EN LA PRODUCCIÓN DEL ESPACIO URBANO DEL ÁREA CENTRAL DE TERESINA}

(PI)

\section{RESUMEN}

El artículo presenta análisis sobre las intervenciones espaciales promovidas a partir de las propuestas contenidas en el Plan Maestro Urbano, desde la perspectiva de los agentes que actúan en la producción espacial del área central de Teresina (PI). Desde esta perspectiva, se adoptaron los siguientes procedimientos: encuesta de referencia teórica, entrevistas y aplicación de cuestionarios. El análisis de datos reveló contradicciones en las acciones de los agentes durante la elaboración y ejecución de las acciones diseñadas para el área central de Teresina. Se concluye que el área central de Teresina asume relevancia para un conjunto diverso de agentes, sin embargo, su acción durante la elaboración de las pautas contenidas en el Plan Maestro

\footnotetext{
${ }^{1}$ Licenciada em Geografia pela Universidade Estadual do Piauí e mestra em Geografia pela Universidade Federal do Piauí. Email: syllsousa@hotmail.com.

2 Doutor em Geografia (UFPE/2009). Docente-Permanente do Mestrado em Geografia e do Mestrado em Desenvolvimento e Meio Ambiente [PRODEMA] da UFPI. Email: facanha@ufpi.edu.br.
}

Sociedade e Território - Natal. Vol. 31, N. 2, p. 199-219

Jul./Dez. de 2019 / ISSN: 2177-8396 
Plano diretor, intervenções e contradições na produção do espaço

contribuyó a la coexistencia de aspectos que generan una producción contradictoria del espacio.

Palabras-chaves: Intervenciones Urbanas. Plan Maestro. Teresina (PI)

\title{
DIRECTOR PLAN, INTERVENTIONS AND CONTRADICTIONS IN THE PRODUCTION OF THE URBAN AREA OF THE CENTRAL AREA OF TERESINA
}

(PI)

\begin{abstract}
The article presents analysis of spatial interventions promoted from the proposals contained in the Urban Master Plan, from the perspective of agents who act in the space production center area of Teresina (PI). From this perspective, the following procedures were adopted theoretical reference survey, interviews and application of questionnaires. The data analysis revealed contradictions in the agents actions during the elaboration and execution of the actions designed for the central area of Teresina. It is concluded that the central area of Teresina assumes relevance for a diverse set of agents, however, their action during the elaboration of the guidelines contained in the Master Plan contributed to the coexistence of aspects that generate a contradictory production of space.
\end{abstract}

Keywords: Urban Interventions. Master Plan. Teresina (PI)

\section{INTRODUÇÃO}

A dinâmica do urbano aponta para a coexistência de alterações frequentes nas relações estabelecidas nos usos dos espaços e das formas que são (re) produzidas para o atendimento de objetivos distintos.

Nesse contexto, objetivou-se com o presente artigo apresentar análises sobre as intervenções promovidas a partir dos debates contidos no Plano Diretor Urbano, sob a ótica dos agentes que atuam na produção espacial da área central de Teresina (PI). Para tanto, os procedimentos metodológicos foram compostos pelo levantamento de referencial teórico constituído por livros, teses, dissertações, e artigos científicos publicados em meios impressos e digitais, ganhando ênfase nesse momento, a análise dos conteúdos do Plano Diretor Municipal de Teresina com vistas ao reconhecimento das proposições do Grupo de Trabalho Revitalização do Centro.

As atividades empíricas abrangeram o recorte espacial que constituiu objeto dos 
trabalhos do Plano Diretor para a área central, com destaque para os projetos pensados e intervenções efetivadas. Ademais, foram aplicados questionários em formulários contendo questões abertas e de múltipla escolha (dicotômicas e tricotômicas). Para a aplicação de questionários foi adotada a amostra aleatória simples e sua variação, correspondendo à amostragem por área, que de acordo Lakatos e Marconi (2009) é utilizada quando a totalidade dos componentes não pode ser conhecida.

Para a definição da amostra adotou-se o erro amostral de 10\% e nível de confiança de 95\%. Assim, a amostra necessária para os transeuntes (população infinita) correspondeu a 98 questionários, os Microempreendedores do Shopping da Cidade (população de 1800, conforme estimativa da administração), 92 questionários, e 14 formulários para os lojistas das ruas Simplício Mendes e Álvaro Mendes. Nesse momento, destaca-se que as observações diretas permitiram a identificação de 77 lojas no recorte, no entanto a maior parcela estava instalada em período posterior às intervenções da Agenda 2015, além disso, alguns estabelecimentos estavam inativos e outros correspondiam às filiais daquelas cujos representantes já haviam respondido aos questionários, soma-se ainda ao grupo de procedimentos o registro fotográfico e a espacialização dos dados.

\section{PLANO DIRETOR E INTERVENÇÕES NA ÁREA CENTRAL DE TERESINA: A AGENDA 2015 EM QUESTÃO}

Na constituição da evolução das características do planejamento e da gestão no Brasil, modificações foram empreendidas durante a década de 1980, período no qual inúmeras reivindicações adquiriram expressividade, especialmente quando se observa a dinâmica das relações no âmbito do urbano. Nesse momento, constata-se que as lutas ensejadas pela defesa de direitos convergiriam para a realização de alterações nos instrumentos integrantes do planejamento assim como nas práticas de gestão urbana.

Nessa trajetória, o Estatuto das Cidades foi aprovado em 2001 como instrumento regulador dos artigos 182 e 183 da Constituição Federal de 1988, sobressaindo-se também a criação do Ministério das Cidades em 2003.

Ao apresentar considerações sobre o Plano Diretor, Souza (2006) defende que estes não precisam ser rígidos ou totalmente detalhados pretendendo a construção da cidade ideal. Os 
planos devem ser reflexos das metas e prioridades, fornecendo instrumentos adequados à realidade de uma cidade, entendida a partir das necessidades existentes. Complementando as afirmações, Lacerda et al. (2005) defendem que o plano deve possuir interface com os outros instrumentos orientados para o planejamento no âmbito da administração municipal e as proposições devem ressaltar os limites e possibilidades das intervenções.

O desenvolvimento dessas análises em escala local aponta para as dinâmicas desencadeadas na Agenda 2015, ganhando ênfase o debate sobre a condução dos processos na área central de Teresina.

Definido como Plano Diretor, a Agenda 2015, Lei municipal nº 3.558/2006 envolveu a existência de diversas contradições, nesse sentido, Lima (2012) observa que embora o Plano Diretor fosse obrigatório pelas deliberações dos novos princípios constitucionais, Teresina ainda era ordenada pela Legislação de 1988 que não contemplava as transformações resultantes da expansão urbana.

Em agosto de 2001 foi iniciada a convocação da sociedade e se instalou o Congresso da Cidade, para elaboração da Agenda 2015, no entanto, a avaliação das contradições que integraram as discussões para elaboração do Plano demonstra a produção de implicações negativas para as características das ações que estavam orientadas para implantação e gestão dos projetos propostos.

No levantamento dos projetos, constata-se que a Agenda 2015 não observou as definições relativas aos investimentos prioritários e ao orçamento participativo, assim como a autoaplicabilidade de instrumentos como as Zonas Especiais de Interesse Social (ZEIS). No âmbito da política de habitação, destaca-se a ausência de instrumentos para demarcação de áreas com infraestrutura, incluindo o direcionamento de áreas centrais para a habitação popular (CARVALHO, 2009).

As características de Teresina, reunidas às investigações relacionadas à área central, apontam destaque para a escala local e as relações existentes entre agentes e processos. Nesse sentido, a área central de Teresina em questão, a partir da (re)produção e intervenções orientadas pela Agenda 2015, congrega o levantamento desse recorte, como pressuposto para o entendimento do seu significado em outros períodos assim como os cenários da atualidade.

Essa associação fundamenta-se nas observações de Carlos (2007), ao entender que a 
cidade como construção humana, deve ser compreendida como um produto histórico-social, constituindo trabalho materializado. Nessa sequência, a acumulação se procede durante toda a formação se relacionado ao espaço em análise, consequentemente a cidade não pode ser desvinculada da sociedade e do momento histórico.

Além disso, quando trabalhada com as áreas centrais, as alterações revelam que se na década de 1970 a centralidade era única, hoje são encontradas a multi e a poli centralidade, fato que implicou em desvalorização imobiliária da área central e valorização de outras áreas, logo diversas atividades passam a ser encontradas em novas centralidades (ALVES, 2015).

A partir das observações que integraram os processos na Agenda 2015, sobressaem-se as discussões das ações para intervenções na área central de Teresina. Logo, considerando o recorte é possível identificar que na apreensão do cenário inercial era apontado o esvaziamento econômico, assinalando uma desvalorização do comércio que concorria para o crescimento das atividades dos ambulantes, além da configuração de outros problemas infraestruturais.

Para o trabalho com a área central na Agenda 2015, foi designado um grupo denominado Revitalização do Centro, que efetuou diagnóstico identificando os equipamentos urbanos existentes, mas também os problemas que dificultavam a manutenção convergindo para a configuração de aspectos considerados como problemáticos.

Nesse momento, as características instaladas foram entendidas como propiciadoras de uma situação caótica mediada pela presença de vendedores ambulantes, problemas no tráfego e na segurança, além da carga e descarga no comércio atacadista, degradação de praças, monumentos e edifícios, poluição sonora e visual, construção de estacionamentos, mediante a demolição de importantes exemplares do patrimônio arquitetônico. Esses contextos foram associados à ausência de Legislação para o Centro e redução de investimentos que passavam a migrar para outros bairros (TERESINA, 2002).

Partindo dos fatores considerados negativos na área central, foi elaborado um "Cenário Desejável" mediado pela execução de iniciativas para revitalização impulsionadas pela associação entre iniciativas público-privadas. Nessa proposta, o setor comercial deveria guardar traços de limpeza, segurança, organização e dinamismo, além disso, deveriam ser observadas ações para a valorização do patrimônio histórico e as melhorias no tráfego (TERESINA, 2002).

Um grupo de propostas foi delineado como subsidiário da formação dos projetos para 
Plano diretor, intervenções e contradições na produção do espaço

intervenção, considerando as necessidades e possibilidades de atuação a partir dos cenários existentes e daqueles objetivados para a configuração na área central (Quadro 1).

\section{Quadro 1: Síntese das proposições da Agenda 2015 para a área central de Teresina}

\begin{tabular}{|c|c|}
\hline \multicolumn{2}{|r|}{ REVITALIZAÇÃO DO CENTRO } \\
\hline PROPOSTA & OBJETIVOS \\
\hline Ame o centro & $\begin{array}{l}\text { Revisão da legislação ambiental } \\
\text { Criação de departamento para a administração do Centro } \\
\text { Criação de ONGs } \\
\text { Articulações entre instituições de diferentes níveis } \\
\text { Promoção de campanhas voltadas para a constituição de educação, } \\
\text { orientada para o patrimônio e a memória }\end{array}$ \\
\hline $\begin{array}{l}\text { Beira de rio Beira de } \\
\text { vida }\end{array}$ & $\begin{array}{l}\text { Implantação do paisagismo às margens do Rio Parnaíba } \\
\text { Ordenamento as atividades informais no Rio Parnaíba }\end{array}$ \\
\hline Abrace uma praça & $\begin{array}{l}\text { Preservação de praças do Centro Histórico a partir do tombamento } \\
\text { Realização de Campanhas voltadas para a adoção de praças }\end{array}$ \\
\hline Comércio Vivo & $\begin{array}{l}\text { Fortalecimento do comércio formal e reorganização do comércio } \\
\text { informal } \\
\text { Associação entre CDL e Prefeitura } \\
\text { Isenções tributárias } \\
\text { Regulamentação dos horários de carga e descarga }\end{array}$ \\
\hline Transitandando & $\begin{array}{l}\text { Promoção de melhorias no acesso de automóveis } \\
\text { Desobstrução de calçadões } \\
\text { Ruas com o sistema de traffic calm } \\
\text { Construção de estacionamentos rotativos } \\
\text { Atenção às paradas de ônibus } \\
\text { Construção de ciclovias. }\end{array}$ \\
\hline Fuá no centro & $\begin{array}{l}\text { Ações para a realização de eventos culturais, } \\
\text { Promoção de segurança e limpeza. }\end{array}$ \\
\hline Moro no centro & $\begin{array}{l}\text { Uso de edificações ociosas para fins residenciais, através de } \\
\text { programas habitacionais desenvolvidos entre a CEF e a PMT. }\end{array}$ \\
\hline
\end{tabular}

Fonte: Elaborado por SILVA, 2013. Adaptado de Teresina (2002).

A observação do quadro expõe as características das conjunturas que integraram os debates em torno das demandas, gerando cenários que permitiram a elaboração dos projetos para a área central que estava com as ruas ocupadas pela atividade informal. Esse contexto constituía alvo de reivindicações dos lojistas, e da parcela da população que não concordava com a disposição adquirida pelas atividades informais.

Essas feições de ocupação predominavam na rua Simplício Mendes, rua Álvaro Mendes 
SOCIEDADE E

TERRITÓRIO
SILVANA, Silvana de Sousa

FAÇANHA, Antônio Cardoso

e na Praça Rio Branco. Os levantamentos contidos no Plano apontavam para dificuldades na visualização das fachadas das lojas e no estabelecimento de fluxos de pedestres e veículos sem barreiras, além do acúmulo de lixo e ausência de manutenção da infraestrutura.

Nesse momento, ganha relevo as reflexões de Dantas (1997) para quem a área central apresenta particularidades fundamentais para o desenvolvimento dessas atividades, como os fluxos contínuos que representam oportunidade de aumento da rentabilidade das vendas. Logo, as ações para intervenções deveriam considerar os significados desses trabalhos, que em muitos exemplos corresponde à única fonte de renda das famílias.

Ademais, destacam-se as considerações de Dias (2006), ao defender que as atividades informais representam respostas para questões como a reduzida oferta no mercado de trabalho, ligada dentre outros às decorrências mencionadas por Reis Filho (2012), ao versar sobre os déficits em diversas questões no Brasil, mas também como observa Yazigi (2000), contemplando os objetivos de agentes que optam por essas atividades.

Deste modo, no trabalho com os desdobramentos das intervenções na área central alguns caminhos foram desenhados. Nesse percurso, durante a formação do projeto para remoção dos ambulantes, a PMT iniciou nos anos de 2005 e 2006 o cadastro de todos os vendedores que atuavam nas ruas e que seriam transferidos para a edificação denominada Shopping da Cidade (Figura 1). 
Plano diretor, intervenções e contradições na produção do espaço urbano da área central de Teresina (PI)

Figura 1: Localização do Shopping da Cidade no Largo do Amparo (Praça da Bandeira)

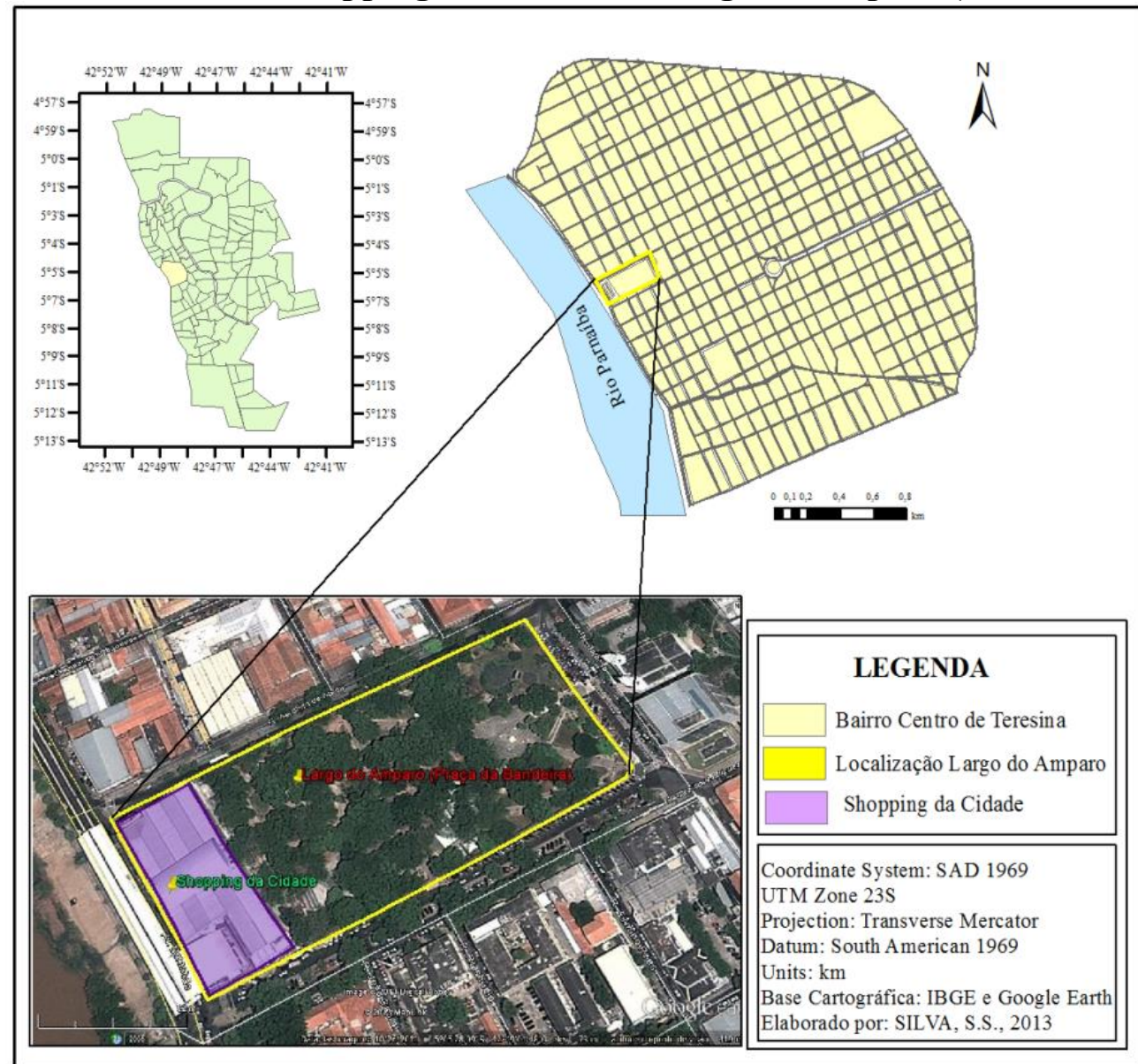

Fonte: Elaborado por SILVA, 2013.

Como pode ser observado na figura 1, o Shopping da Cidade foi edificado em um trecho integrante do Largo do Amparo constituindo uma construção que desconsiderou os referenciais históricos e arquitetônicos que compõem o local que engloba o conjunto das primeiras edificações da cidade durante o plano em tabuleiro de xadrez.

Nesse momento, destaca-se o debate teórico acerca das características do planejamento e da gestão urbanos para fundamentação das orientações apresentadas para esses instrumentos e as implicações para a produção do espaço.

\section{PLANEJAMENTO E DIRETRIZES PARA INTERVENÇÕES NO ESPAÇO URBANO}

O entendimento da dinâmica espacial mediado pelos debates sob a ótica das abordagens geográficas possibilita a construção de observações que englobam o reconhecimento de 
contextos diversificados que revelam a existência de ações capazes de imprimir características que conduzem a observações das similitudes e contradições integrantes do urbano.

Apoiando-se nos debates relacionados ao espaço urbano, é sublinhada a análise teórica da produção e reprodução das dinâmicas sócio-espaciais. Deste modo, Carlos (2012) defende que o papel da localização deve ser reconhecido de forma relativizada predominando um enfoque que envolve a apropriação, a produção e a reprodução dos conteúdos sociais. A autora indica que a configuração desse entendimento engloba a passagem da noção de localização para a organização do espaço, e de organização à produção.

Tecendo considerações sobre a produção do espaço, Corrêa (2012, p. 43) salienta que esse processo é "[...] consequência da ação de agentes sociais concretos, históricos, dotados de interesses, estratégias e práticas espaciais próprias portadores de contradições e geradores de conflitos entre eles mesmos e com outros segmentos da sociedade".

As observações supramencionadas sinalizam que a dinâmica resultante da inter-relação entre os elementos que compõem o espaço urbano respaldam a configuração de um contínuo processo de produção. $\mathrm{O}$ grupo ampliado de objetivos que integram essa produção revela a composição de espaços, com padrões que reafirmam a instituição de um urbano permeado pela diversidade de intervenções relacionadas a estratégias que podem gerar conflitos.

Na discussão sobre o planejamento urbano, Souza e Rodrigues (2004) ressaltam que entre os desafios gerados por essa atividade, está a exigência da efetivação de reflexões e análises, ligadas às situações que podem ser verificadas atualmente. Nesse sentido, essa prática produz subsídios para o levantamento e compreensão das possibilidades que se configurarão, representando alterações nas ações de prognóstico.

Conforme os autores supramencionados, o planejamento frequentemente é alvo de críticas relacionadas à defesa da impossibilidade de elaboração de cenários para o futuro. Além disso, em muitos exemplos, observa-se a predominância da confiança no emprego de técnicas estatísticas e matemáticas, como recursos que oportunizariam o desenvolvimento de previsões dotadas de exatidão.

Diante desse quadro, Souza e Rodrigues (2004) defendem que o desafio que se impõe corresponde ao trabalho de realização de prognósticos contemplando os processos que se desdobram ao longo da história, abordando-a como um processo aberto que, por conseguinte 
desperta para múltiplas possibilidades.

No entanto, quando se discute o papel assumido pelo planejamento, algumas contradições são reveladas e em muitos momentos são foco de críticas que defendem a necessidade de observações detalhadas para que o processo possa envolver qualidades previamente pensadas, possibilitando maior atribuição de significado a cada etapa que integra o processo. Recebem importância nessa análise a participação diferenciada dos agentes sociais, as características efetivamente realizadas, e o acompanhamento mediado pela gestão.

Esse debate é reforçado por Alves (2015), ao ressaltar que a construção dos consensos por parte do Estado ligado à iniciativa privada, dispersa os conflitos da luta entre o direito à propriedade e o direito aos usos das populações que têm nesse espaço a possibilidade do direito à moradia, trabalho e outras necessidades cotidianas.

No trajeto com o Planejamento Urbano, Souza e Rodrigues (2004) destacam que este pode conter novas configurações, fato que indica que o acesso aos debates pode não ficar restrito a alguns grupos, pois o Estado também pode ser gerido por forças políticas para mudanças. Além disso, as preposições deveriam considerar as características dos agentes que atuam na reprodução do espaço urbano, permitindo a configuração de dinâmicas compostas por aspectos que admitiriam a condução das atividades medidas pelas propostas e lutas provenientes da sociedade civil, assinalando novas realidades.

As anotações correlatas ao planejamento e gestão, pressupõem discussões que compõem a dinâmica de relações integrantes desses encaminhamentos, que envolvem as atividades no urbano. Englobam ainda agentes cujos anseios apresentam diferenciações na medida em que representam expectativas existentes, com características adequadas aos objetivos inerentes como subsídio para orientação das proposições, cuja efetivação poderá ser acompanhada e reivindicada nos períodos preestabelecidos para execução das ações.

Somando-se às observações, buscou-se a construção de conhecimentos relacionados aos papéis assumidos pelas intervenções para agentes que estão diretamente associados ao processo de proposições para a Agenda 2015 e as intervenções realizadas. 
SOCIEDADE E

TERRITÓRIO
SILVANA, Silvana de Sousa

FAÇANHA, Antônio Cardoso

\section{PAPEL DOS AGENTES NAS INTERVENÇÕES URBANAS DA ÁREA CENTRAL DE TERESINA (PI)}

As atividades de campo consideraram a busca pelo estabelecimento das relações existentes entre as intervenções urbanas resultantes da Agenda 2015, e o papel para os agentes que atuam na área central além das relações sócio-espaciais que caracterizam esse recorte.

Destarte, o trabalho com os microempreendedores do Shopping da Cidade, revelou que apenas 38\% do universo amostral participaram de reuniões durante a elaboração da Agenda 2015. Visando a caracterização dos microempreendedores, constatou-se o deslocamento cotidiano de outros bairros das diferentes zonas da cidade e do município maranhense limítrofe, para desenvolver as atividades na área central de Teresina (Figura 2).

A figura 2 aponta que o desenvolvimento das atividades no Shopping da Cidade constitui importante fonte de empregos, exercendo atratividade sobre os diferentes bairros da cidade podendo ser observado o deslocamento de bairros distantes da área central, além daqueles oriundos do município de Timon (MA).

A associação entre o deslocamento das atividades para o Shopping da Cidade e as influências no fluxo de vendas, demonstrou que para $18 \%$ dos pesquisados as vendas sofreram aumento, para $37 \%$ elas permaneceram iguais e para $45 \%$ elas diminuíram. A leitura dos percentuais associados às observações diretas demonstra que a redução das vendas é indicada especialmente pelos vendedores que não estão instalados no térreo que possui maior circulação de clientes.

A permanência no percentual de vendas em detrimento do acréscimo no período estudado, em alguns exemplos, foi atribuída à própria dinâmica que compõe a atividade comercial. Dessa maneira, a relação entre o acréscimo/redução não está ligada ao local de comercialização, mas ao período do ano. Como exemplo, observa-se que nos momentos antecedentes de datas comemorativas, geralmente as vendas verificam expressivo acréscimo. Ademais, as observações demonstram que a ausência de diversificação de mercadorias em alguns boxes, pode atuar motivando os baixos índices de vendas. 
Plano diretor, intervenções e contradições na produção do espaço urbano da área central de Teresina (PI)

Figura 2: Bairros de residência dos microempreendedores do Shopping da Cidade

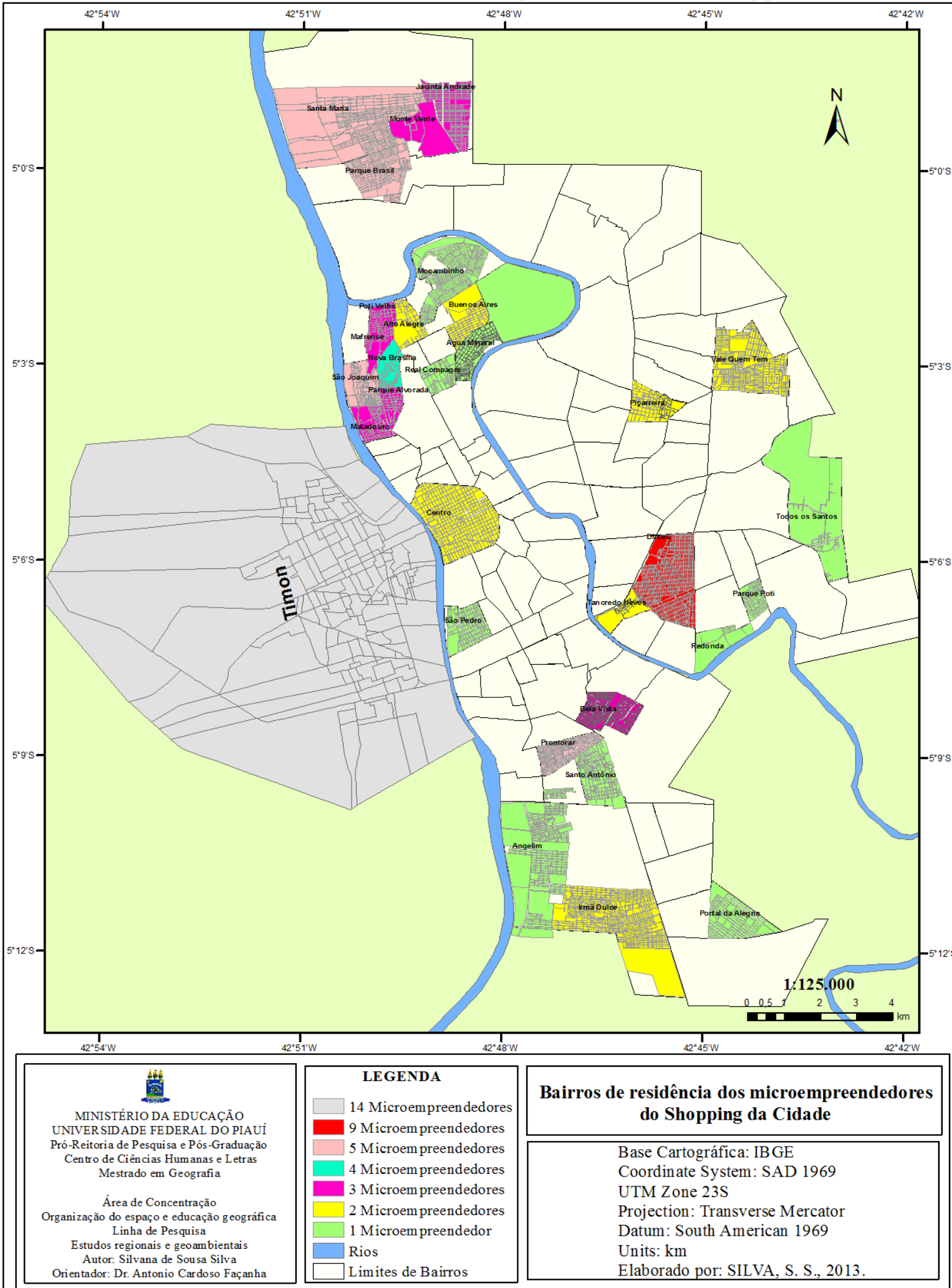

Fonte: Elaborado por SILVA, 2013, a partir de pesquisa direta, set. 2013. 
Complementando as relações das vendas, 38\% afirmaram que o perfil dos clientes mudou após a transferência para o Shopping da Cidade. Por outro lado, 56\% dos microempreendedores não modificaram as mercadorias e $46 \%$ sentiu a necessidade de alterações no tipo de produtos, visando atender as características compostas pela diversificação de consumidores que estabeleceram novas exigências, além de ampliação do volume de mercadorias.

A multiplicidade na origem dos consumidores dos produtos ofertados pelas atividades comerciais desenvolvidas na área central foi verificada também pelos lojistas, na medida em que para $93 \%$ dos pesquisados existe um contínuo fluxo de clientes provenientes de outros municípios.

Ampliando as perspectivas para debates das realidades constituídas após as intervenções decorrentes das propostas da Agenda 2015, 64\% dos lojistas afirmaram que os ambulantes nas ruas representavam entraves para os estabelecimentos comerciais. Além disso, para 43\%, o número de consumidores aumentou após as intervenções, no entanto, quando verificada a participação nas discussões da Agenda, apenas 21\% integraram as reuniões durante os Seminários, sugerindo o papel expressivo assumido pelas associações representativas.

A diversificação de consumidores sob a ótica de lojistas e microempreendedores, estende-se para a localização da área central e o papel da função comercial que atrai interessados nos produtos ofertados. Essa observação aponta o predomínio do comércio e dos serviços que caracterizam Teresina desde a transferência da capital, como salientado por Martins (2003), Veloso Filho et. al. (2011) e Façanha (2009), fato que demonstra o papel do setor terciário para a economia piauiense, como destacado por Rebelo (2000).

O conjunto de observações que denotam a diversidade de usos e características dos agentes na área central é reforçado pelo reconhecimento da origem dos transeuntes que frequentam o recorte (Figura 3). 
Plano diretor, intervenções e contradições na produção do espaço urbano da área central de Teresina (PI)

Figura 3: Bairros/municípios de residência dos transeuntes

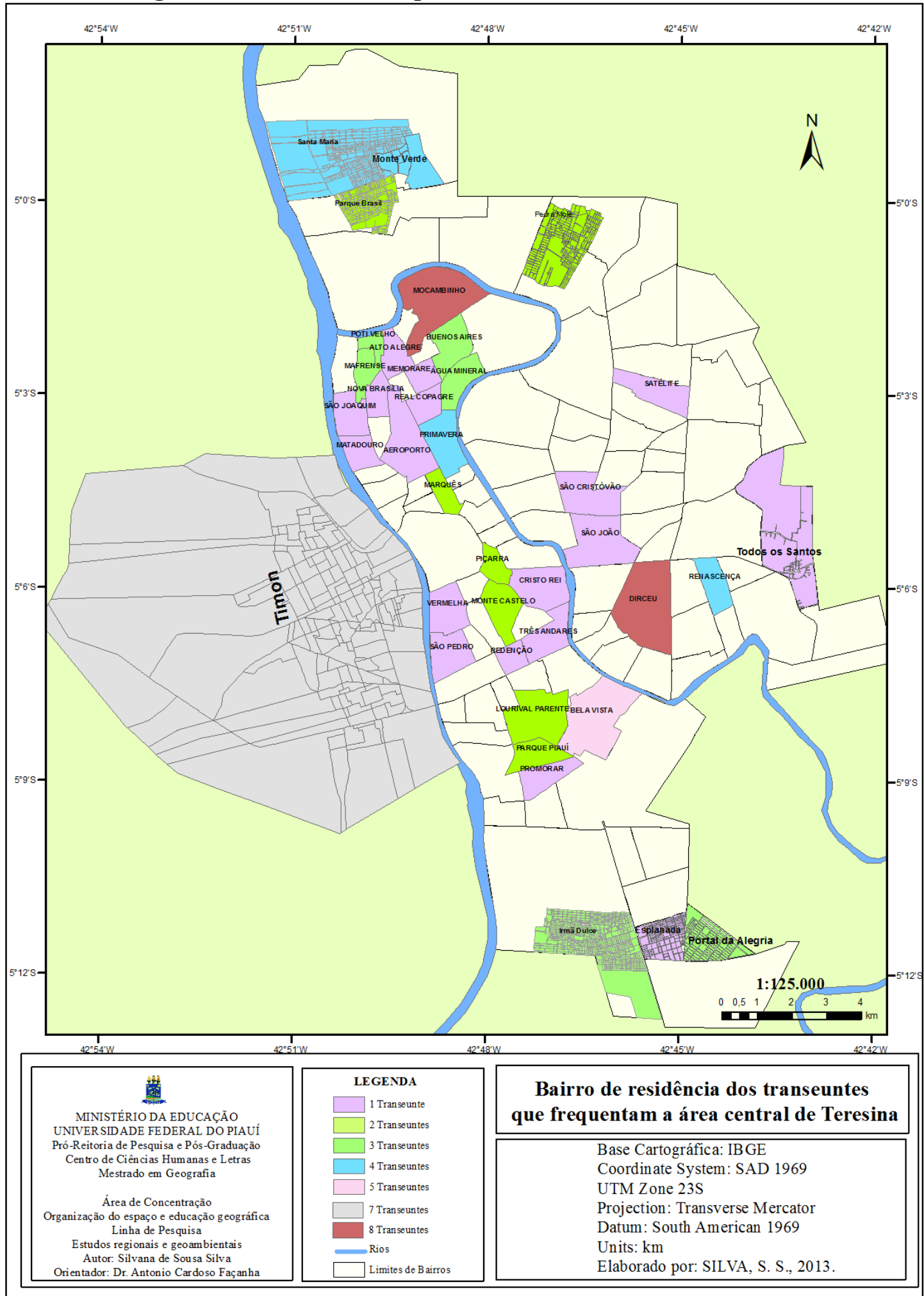

Fonte: Elaborado por SILVA, 2013. 
A abordagem conduz à constatação da existência de um fluxo advindo de bairros diversificados, além de municípios como Timon (MA), União (PI), Altos (PI) e Nazária (PI). No que tange as ações efetivadas pelos questionados destacou-se a realização de compras uma vez que esta é a oferta predominante na área central. Ganhando destaque também a procura por serviços, cuja presença em alguns bairros ainda é reduzida, tais como os bancos e os serviços de saúde, estes são aludidos especialmente pela ligação com o polo de saúde instalado no Bairro Centro. Reiterando os dados do gráfico, verifica-se que para $41 \%$ dos pesquisados as atividades desenvolvidas na área central não poderiam ser praticadas nos seus respectivos bairros, enquanto para $31 \%$ apenas algumas delas e para $29 \%$ essas atividades poderiam ser realizadas.

Buscando identificar o papel das intervenções para os transeuntes, verificou-se que a totalidade destes frequentava a área central antes das ações, não atribuindo assim o uso aos processos efetivados após a Agenda 2015. Do percentual, 52\% não concordavam com o desenvolvimento das vendas informais nas ruas, $28 \%$ concordavam e $20 \%$ mostraram-se indiferente uma vez que a referida atividade não interferia nos usos. Constatou-se também que $70 \%$ frequentavam o Shopping da Cidade. Os dados traduzem a dinâmica que integra a (re)produção espacial na área central de Teresina, demonstrando que as intervenções possuem algumas implicações para o uso dos espaços, mas também ressalvas. Assim, a continuidade das análises englobou os encaminhamentos delineados no âmbito das exigências ainda existentes.

Nessa perspectiva, no Shopping da Cidade foi verificado que para $76 \%$ dos microempreendedores os problemas permanecem, e em sua maior parcela está relacionado aos aspectos infraestruturais relacionados às dificuldades na segurança, existência de pouca ventilação em alguns corredores, bebedouros e energia ruins, com ausência de luz de emergência e banheiros localizados em apenas um lado. Foi citada ainda a existência de alagamentos em períodos chuvosos e problemas na divisão de corredores, pois alguns são mais largos que os outros.

São partilhadas também sugestões envolvendo a possibilidade de organização dos corredores por seção e reclamações quanto às taxas pagas e inexistência de passarela ligando à estação do metrô. Os problemas notados podem estar relacionados à desconsideração dos objetivos dos microempreendedores durante as definições dos direcionamentos das intervenções, como apontado em entrevista com representante da Secretaria Municipal de 
Planejamento e do Grupo de Trabalho Revitalização do Centro, mas também ao estabelecimento de prioridades pela gestão municipal.

Embora com a existência dos problemas citados, 62\% afirmaram que não voltariam a comercializar os produtos nas ruas ou em outros locais, enquanto $38 \%$ destacaram que abandonariam o Shopping da Cidade, percentual representado pelo grupo insatisfeito com o volume de vendas. Por outro lado, $82 \%$ afirmaram que as vendas não seriam melhores nos seus respectivos bairros, na medida em que não são encontradas dinamicidades nos fluxos, além de maior incidência de violência e ausência de infraestrutura, reafirmando os elementos dinamizadores da área central, em detrimento dos processos existentes em outros locais.

Somando-se ainda o menor poder de compra da população residente em alguns bairros, fato que levaria a diminuição das vendas, associadas à ausência de pessoas de outras cidades para adquirir produtos.

No levantamento de características das intervenções para os lojistas, verificou-se que para 79\% o resultado das intervenções nas Ruas Simplício Mendes e Álvaro Mendes podem ser considerados bons e para $21 \%$ ótimos. Entretanto, $71 \%$ revelaram que a área central ainda necessita de intervenções na segurança, proibição de circulação de carros nas vias centrais, intervenções em calçadas, existência de fiscalização e controle da poluição sonora.

A necessidade de intervenções foi externada ainda por 57\% dos transeuntes, que observam carências na segurança, limpeza, climatização de ruas, maior quantidade de ônibus, cuidado com calçadas e praças, instalação de equipamentos para lazer, implantação de mais árvores, incentivando os atrativos culturais, melhorarias no trânsito, instalação estacionamentos, posto policial, redução da poluição sonora e visual, desenvolvimento de cuidados com o patrimônio histórico e disponibilização de mais espaço para pedestres.

São indicadas demandas para intervenções no Mercado Central, exposição do artesanato local, instalação de mais lugares para guardar bicicletas, coibição de estacionamento em locais errados, proibição da circulação nas principais ruas, melhoraria sinalização, na jardinagem, na fiscalização das lojas que jogam os lixos na rua e organização das paradas de ônibus.

Ademais, na composição de anseios por intervenções, destaca-se a segurança compreendida por $50 \%$ dos lojistas como ruim, $14 \%$ péssima, $29 \%$ boa e $7 \%$ ótima. E por $55 \%$ dos transeuntes como ruim, $31 \%$ péssima, $14 \%$ boa. 
SOCIEDADE E

TERRITÓRIO
SILVANA, Silvana de Sousa

FAÇANHA, Antônio Cardoso

\section{CONCLUSÃO}

A dinamicidade que caracteriza as relações desenvolvidas no espaço urbano é composta por processos que refletem a atuação dos diferentes agentes sociais, mediados pela busca da resposta aos objetivos que se originam nos anseios diários.

$\mathrm{Na}$ consideração das estratégias, dos conflitos e das realidades, foi possível indicar que quando contemplada a área central, os processos realizados no âmbito da construção da Agenda 2015 demonstraram a atuação desigual dos agentes que apresentaram interesses associados ao recorte. A assertiva é verificada, por exemplo, quando algumas associações representativas abandonaram a participação nos Seminários para discussão das proposições de atuação.

Essas características não se restringiram aos debates iniciais, sendo encontradas ainda nas afirmações dos entrevistados na atualidade, quando pode ser constatada por um lado a continuidade de debates em reuniões, com algumas entidades representativas além da expressiva dificuldade para o acesso de outros agentes para exposição de problemas que permanecem, como àqueles no Shopping da Cidade.

As análises empíricas demonstraram que as intervenções urbanas realizadas a partir das disposições da Agenda 2015 atuaram preponderantemente para o atendimento dos objetivos estabelecidos por determinados agentes e suas Associações, fato exemplificado nas assertivas sobre as ações para a remoção de barracas e melhorias nas ruas como recurso frequentemente citado como fundamental para a melhoria das vendas das lojas na área central.

Contemplando as intervenções efetivadas, a análise da transferência dos ambulantes para o Shopping da Cidade representou inicialmente alvo de intensas discussões e rejeição, mas a avaliação na atualidade incorpora também aspectos como a comodidade e a defesa contra a chuva ou do calor, constituindo indicadores que atuam positivamente, sob o ponto de vista dos permissionários.

A dialética que compõe as relações nas práticas dos microempreendedores revela que a dinâmica vivenciada nesse espaço encerra a desigualdade das relações de mercado. Logo é possível identificar vendedores com acentuada fragilidade na competição, especialmente reforçada pela necessidade de modificação das mercadorias para atender aos consumidores de outros períodos, mas também os novos.

Esses contextos atuam influenciando em muitos casos a recusa pela presença no 
Shopping da Cidade. Por outro lado, é possível observar a existência de relações diversificadas que são expressas, por exemplo, na identificação de boxes que funcionam mediante a contratação de funcionários e aqueles que apontam as vendas no local como única fonte de renda, fornecendo subsídios necessários para a manutenção da família, além da grande quantidade e diversidade de mercadorias ofertadas por alguns microempreendedores.

A dinâmica comercial está explícita ainda nos processos que envolvem a comercialização dos boxes, constatado através dos vendedores com atuação recente no Shopping da Cidade. As observações demonstraram as relações de mercado, revelando que a atividade comercial no local não forma resposta exclusiva para a ausência de vagas no mercado de trabalho.

Foi possível constatar também que apesar das experiências das relações comerciais ampliadas a adaptação ainda encontra empecilhos, que envolvem desde a recusa e ausência de identificação com as atividades instaladas no modelo da edificação à inferência das ruas enquanto facilitadoras do crescimento das vendas, até o apontamento de problemas infraestruturais, que dificultam o desenvolvimento das atividades ou ainda implicam na pequena proporção de venda em determinados pisos.

Ainda integrando as realidades configuradas a partir da Agenda 2015 na área central, a abordagem com os lojistas apontou a presença dos ambulantes como entraves para as vendas. A apreciação da dinâmica desses agentes revelou também a existência de rotatividade nos negócios, notado no frequente deslocamento de estabelecimentos e instalação de outros.

Por outro lado, é visível a permanência ou chegada de grandes representantes do setor varejista que vislumbram a diversidade de usos presentes na área central, como potencializadores das vendas. Por conseguinte, constata-se que mesmo com a instalação dos Shoppings Centers e expansão de outras áreas comerciais, as características do comércio associada aos serviços desenvolvidos na área central são atrativos para a população, influenciando a localização de lojas na área central.

Constatou-se que a área central é diretamente vinculada às funções que caracterizam esse recorte, atraindo fluxos contínuos de população que se desloca em busca de serviços, mas também constituindo o local de trabalho para muitos dos questionados. Mesmo com a relevância assumida, a frequência à área central não foi diretamente associada às intervenções. Estas por 
sua vez são reconhecidas como relevantes, na medida em que facilitam o deslocamento diário imprimindo novas alternativas.

Diante das análises ensejadas, verificou-se que a área central guarda centralidade na medida em que congrega diversas atividades oferecidas em Teresina, especialmente as comerciais e os serviços. Essa importância expressa extensão que transcende os limites da cidade, especialmente quando considerada as relações com os municípios maranhenses, com ênfase para Timon.

\section{REFERÊNCIAS}

ALVES, Glória. Transformações e resistências nos centros urbanos. In: CARLOS, Ana Fani A. A crise urbana. São Paulo: Contexto, 2015.p 143-152.

Brasil.Lei no 10.257, de 10 de junho de 2001. Regulamenta os arts. 182 e 183 da Constituição Federal, estabelece diretrizes gerais da política urbana e dá outras providências. Diário Oficial [da] República Federativa do Brasil, Poder Executivo, Brasília, DF, 10 jun. 2001 a. Disponível em: < http://www.planalto.gov.br/ccivil_03/leis/LEIS_2001/L10257.htm>. Acesso em: 03 fev. 2013.

Carlos, Ana F. A. Da "organização" à “produção" do espaço no movimento do pensamento geográfico. In: CARLOS, Ana F. A.; SOUZA, Marcelo L de; SPÓSITO, Maria E. B. (Org.). A produção do espaço urbano: agentes e processos, escalas e desafios. Contexto: São Paulo, 2012. p. 53-74.

O espaço urbano: novos escritos sobre a cidade. São Paulo: Labur, 2007.

Carvalho, Luis E. Relatório Estadual Piauí. Teresina: Rede de avaliação e capacitação para implementação dos planos diretores, 2009.

Corrêa, Roberto L. Sobre Agentes sociais, escala e produção do espaço: um texto para discussão. In: CARLOS, Ana F. A.; SOUZA, Marcelo L de; SPÓSITO, Maria E. B. (Org.). A produção do espaço urbano: agentes e processos, escalas e desafios. Contexto: São Paulo, 2012. p. 41-52.

Dias, Cid de C. Piauí projetos estruturantes. Teresina: Alínea, 2006.

Façanha, Antonio C. Desenvolvimento territorial recente em espaços sub-regionais dinâmicos no Piauí. 2009. 226 f. Tese (Doutorado em Geografia)- Universidade Federal de Pernambuco, Recife, 2009. 
Instituto Brasileiro de Geografia e Estatística. Geociências Bases Cartográficas em Shapefiles. Disponível em:

$<$ http://www.ibge.gov.br/home/geociencias/cartografia/default.shtm>. Acesso em: 15 fev. 2013.

Lakatos, Eva M.; Marconi, Marina de A. Técnicas de pesquisa. 7. ed. São Paulo: Atlas, 2009.

Lacerda, Norma; Marinho, Geraldo; Bahia, Clara; Queiroz, Paulo e Pecchio, Rubén. Planos diretores municipais: aspectos legais e conceituais. Revista brasileira de Estudos Urbanos e Regionais, v. 7, n. 1, 2005. Disponível em:<

http://www.anpur.org.br/revista/rbeur/index.php/rbeur/article/view/135>. Acesso em: 14 abr. 2013.

Lima, Antonia J. de. Planos diretores e os dilemas da governança urbana no Brasil. Textos e contextos. Porto Alegre, v. 11, n. 2, p. 362-375, 2012. Disponível em:

$<$ http://revistaseletronicas.pucrs.br/ojs/index.php/fass/article/view/11837/8643>. Acesso em: 30 jun. 2013.

Martins, Agenor de S. et. al. Piauí: evolução e desenvolvimento. 3. ed. rev. Teresina: Fundação CEPRO, 2003. p. 131-220.

Rebelo, Emília M. de C. G. A urbanização no Piauí. Carta CEPRO. Teresina, v. 18, n. 1, p.99-114, 2000.

Reis Filho, Antonio A. dos. Análise integrada do geoprocessamento na expansão urbana de Teresina com base no Estatuto das Cidades: estudo de potencialidades, restrições e conflito de interesse. 2012. 278 f. Tese (Doutorado em Geografia)-Universidade Federal de Minas Gerais, Belo Horizonte, 2012.

Santos, Glauber E. de O. Cálculo amostral: calculadora on-line. 2013. Disponível em: $<$ http://www.calculoamostral.vai.la>. Acesso em: 10 jul. 2013.

Souza, Marcelo L. de; RODRIGUES, Glauco B. Planejamento urbano e ativismos sociais. São Paulo: UNESP, 2004.

A cidade, a palavra e o poder: práticas, imaginários e discursos heterônomos e autônomos na produção do espaço urbano. In: CARLOS, Ana F. A.; SOUZA, Marcelo L de; SPÓSITO, Maria E. B. (Org.). A produção do espaço urbano: agentes e processos, escalas e desafios. São Paulo: Contexto, 2012. p. 147-166.

SOUZA, Marcelo L. de. Mudar a cidade: uma introdução crítica ao planejamento e à gestão urbanos.4. ed. Rio de Janeiro: Bertrand Brasil, 2006.

Teresina. Secretaria Municipal de Planejamento e Coordenação Geral. Teresina: Agenda 2015 - Plano de Desenvolvimento Sustentável. Teresina, 2002. 
SOCIEDADE E

TERRITÓRIO
SILVANA, Silvana de Sousa

FAÇANHA, Antônio Cardoso

Veloso Filho, Francisco de A; Silva, Cleber de D. P. da; Silva, Fernanda R. V. e; Carvalho, Francisco P. A. de. Impactos dos grandes projetos federais e reflexões para a formulação das políticas de desenvolvimento no Estado do Piauí. In: SILVA, Maria L. da e APOLINÁRIO, Valdênia. (Org.). Impactos dos grandes projetos federais sobre os estados do Nordeste.

Natal: EDUFRN, 2011. p. 245-257.

Yazigi, Eduardo. O mundo das calçadas. São Paulo: Humanitas e Imprensa Oficial do Estado de São Paulo, 2000.

Recebido em Fevereiro de 2019

Aprovado em Agosto de 2019

Publicado em Dezembro de 2019 